\title{
Intraoperative image guidance for cervical spine surgery
}

\author{
Sertac Kirnaz ${ }^{1 \#}$, Harry Gebhard ${ }^{2,3 \#}$, Taylor Wong ${ }^{1}$, Raj Nangunoori ${ }^{1}$, Franziska Anna Schmidt ${ }^{1}$, Kosuke Sato ${ }^{4}$, \\ Roger Härtl ${ }^{1}$
}

${ }^{1}$ Weill Cornell Brain and Spine Center, Department of Neurological Surgery, New York-Presbyterian/Weill Cornell Medicine, New York, NY, USA; ${ }^{2}$ Department of Surgery, Canton Hospital Baden, Switzerland; ${ }^{3}$ Department of Trauma, University Hospital Zurich, University of Zurich, Switzerland; ${ }^{4}$ Hospital for Special Surgery, New York, NY, USA

Contributions: (I) Conception and design: S Kirnaz, H Gebhard, R Nangunoori; (II) Administrative support: S Kirnaz, H Gebhard, T Wong, K Sato; (III) Provision of study materials or patients: S Kirnaz, H Gebhard; (IV) Collection and assembly of data: S Kirnaz, H Gebhard, T Wong, FA Schmidt; (V) Data analysis and interpretation: S Kirnaz, H Gebhard; (VI) Manuscript writing: All authors; (VII) Final approval of manuscript: All authors.

\#These authors contributed equally to this work.

Correspondence to: Roger Härtl, MD. Department of Neurological Surgery, Weill Cornell Brain and Spine Center, New York-Presbyterian Hospital, 525 East 68th Street, Box 99, New York, NY 10065, USA. Email: roh9005@med.cornell.edu.

\begin{abstract}
Intraoperative image-guidance in spinal surgery has been influenced by various technological developments in imaging science since the early 1990s. The technology has evolved from simple fluoroscopic-based guidance to state-of-art intraoperative computed tomography (iCT)-based navigation systems. Although the intraoperative navigation is more commonly used in thoracolumbar spine surgery, this newer imaging platform has rapidly gained popularity in cervical approaches. The purpose of this manuscript is to address the applications of advanced image-guidance in cervical spine surgery and to describe the use of intraoperative neuro-navigation in surgical planning and execution. In this review, we aim to cover the following surgical techniques: anterior cervical approaches, atlanto-axial fixation, subaxial instrumentation, percutaneous interfacet cage implantation as well as minimally invasive posterior cervical foraminotomy (PCF) and unilateral laminotomy for bilateral decompression. The currently available data suggested that the use of $3 \mathrm{D}$ navigation significantly reduces the screw malposition, operative time, mean blood loss, radiation exposure, and complication rates in comparison to the conventional fluoroscopic-guidance. With the advancements in technology and surgical techniques, $3 \mathrm{D}$ navigation has potential to replace conventional fluoroscopy completely.
\end{abstract}

Keywords: Navigation; robotics; cervical spine; unilateral laminotomy for bilateral decompression (ULBD); fusion

Submitted Jan 30, 2020. Accepted for publication Jun 11, 2020.

doi: $10.21037 / \mathrm{atm}-20-1101$

View this article at: http://dx.doi.org/10.21037/atm-20-1101

\section{Introduction}

Intraoperative image-guidance in spinal surgery has been influenced by various technological developments in imaging science since the early 1990s. This technology has evolved from simple fluoroscopic-based guidance to state-of-art intraoperative computed tomography (iCT)based navigation systems $(1,2)$. The use of computer-based intraoperative navigation allows for a better understanding of complex spinal anatomy, higher accuracy, reduced radiation exposure, shorter operative time, and decreased complication rates (3-5). It is mainly used for localization, instrumentation, incision planning, and ensuring the adequacy of decompression in several different surgical techniques. Minimally invasive spine surgery has greatly benefited from these advancements due to the limited direct visualization inherent to this technique (6).

Although intraoperative navigation is more commonly 
used in thoracolumbar spine surgery, it has rapidly gained popularity in cervical approaches (6). The cervical anatomy poses unique surgical challenges, particularly in high cervical levels due to the presence of the spinal cord, nerve roots, vertebral arteries as well as its relatively smaller bony fixation points for instrumentation (7). Moreover, the appropriate localization of index levels may be more difficult in the lower cervical spine with standard intraoperative fluoroscopy. For aforementioned reasons, the use of intraoperative $3 \mathrm{D}$ navigation offers many opportunities in cervical spine surgery, specifically with streamlining surgical workflow, decreasing invasiveness, and improving the accuracy of instrumentation (8).

The purpose of this review is to address the applications of advanced image-guidance in cervical spine surgery and to describe the use of intraoperative neuronavigation in surgical planning and execution. In this review, we aim to cover the following surgical techniques: anterior cervical approaches, atlanto-axial fixation, subaxial instrumentation, percutaneous interfacet cage implantation as well as minimally invasive posterior cervical foraminotomy (PCF) and unilateral laminotomy for bilateral decompression.

\section{Anterior cervical approaches}

After its first introduction in 1958, anterior cervical discectomy and fusion (ACDF) has become one of the most commonly performed surgical procedures for single and multi-level cervical degenerative disc disease, infection, and neoplastic pathologies (9-12). Although conventional ACDF with fluoroscopy is a well-established procedure, there are some complications including dysphagia and degeneration of the adjacent segments. Comparatively, endoscopic procedures with smaller incision size have been successfully applied which could reduce the risk of dysphagia and adjacent segment degeneration $(13,14)$. As such, navigation technology is expected to provide important anatomic information, particularly in minimally invasive techniques $(15,16)$. Although the available data on the utilization of this technology for anterior cervical surgery is limited, the advantages have been described for several special circumstances including corpectomies, tumor resections, revision surgeries, and cases that involve the C-T junction (7).

The usage of navigation essentially requires placing the reference array with stability. Placement of the reference array can be challenging in anterior cervical procedures due to the supine positioning of the patient and a lack of reliable bony landmarks (7). For that reason, the reference array is often attached to either a skull clamp head-holder or surgical table (17). Alternatively, a skin-fixed dynamic reference frame can be used as well (18).

In the lower cervical and upper thoracic spine, visualization of the levels with fluoroscopic-guidance can be more difficult. Therefore, in these particular cases, the risk of wrong level surgery can be improved by using $3 \mathrm{D}$ navigation (17). 3D navigation can significantly decrease operating time and radiation exposure to the OR staff by preventing frequent interruptions from multiple fluoroscopy scans $(8,19)$. Specifically, revision surgeries can pose as technical challenges due to an elevated risk of complications in the setting of disturbed anatomy and absence of bony structures (7). In such cases, the benefits of navigation can be greater. For anterior cervical corpectomies, the extent of bone removal and middle point of the vertebral body can be determined with $3 \mathrm{D}$ navigation after the anterior aspect of spine has been exposed, allowing surgeons to perform a wide and symmetric corpectomy without injuring vertebral arteries $(7,17)$ (Figure 1). In tumor cases, navigation plays a key role in localizing both the vertebral arteries and borders of the soft-tissue or osseous mass (7). Insertion of anterior cervical screws cage can be planned with navigationguidance and the accuracy can be comparable to insertion with fluoroscopy (20-22).

\section{Posterior cervical approaches}

\section{C1-2 fusion}

The atlantoaxial area differs from the other functional units of the lower cervical spine by its unique features (23). Several pathologies such as trauma, rheumatoid arthritis, infections, tumors, congenital malformations, genetic disorders with inherent ligamentous laxity, and degenerative conditions can lead to atlantoaxial instability $(24,25)$. For aforementioned cases, many different C1-2 fixation and fusion techniques were described with the aim to re-establish stabilization (26-28). Compared to other atlantoaxial fixation options, the highest biomechanical stability and fusion rates are provided by posterior transarticular screws C1/2, which were described by Magerl et al. in 1987 (29,30). However, anatomical and radiological studies showed that $18 \%$ to $23 \%$ of patients may not be suitable candidates for posterior C1-2 transarticular screw fixation due to the anomalous course of the vertebral artery, especially in cases of a high-riding transverse foramen at the $\mathrm{C} 2$ level; therefore, it's essential to assess the anatomy 

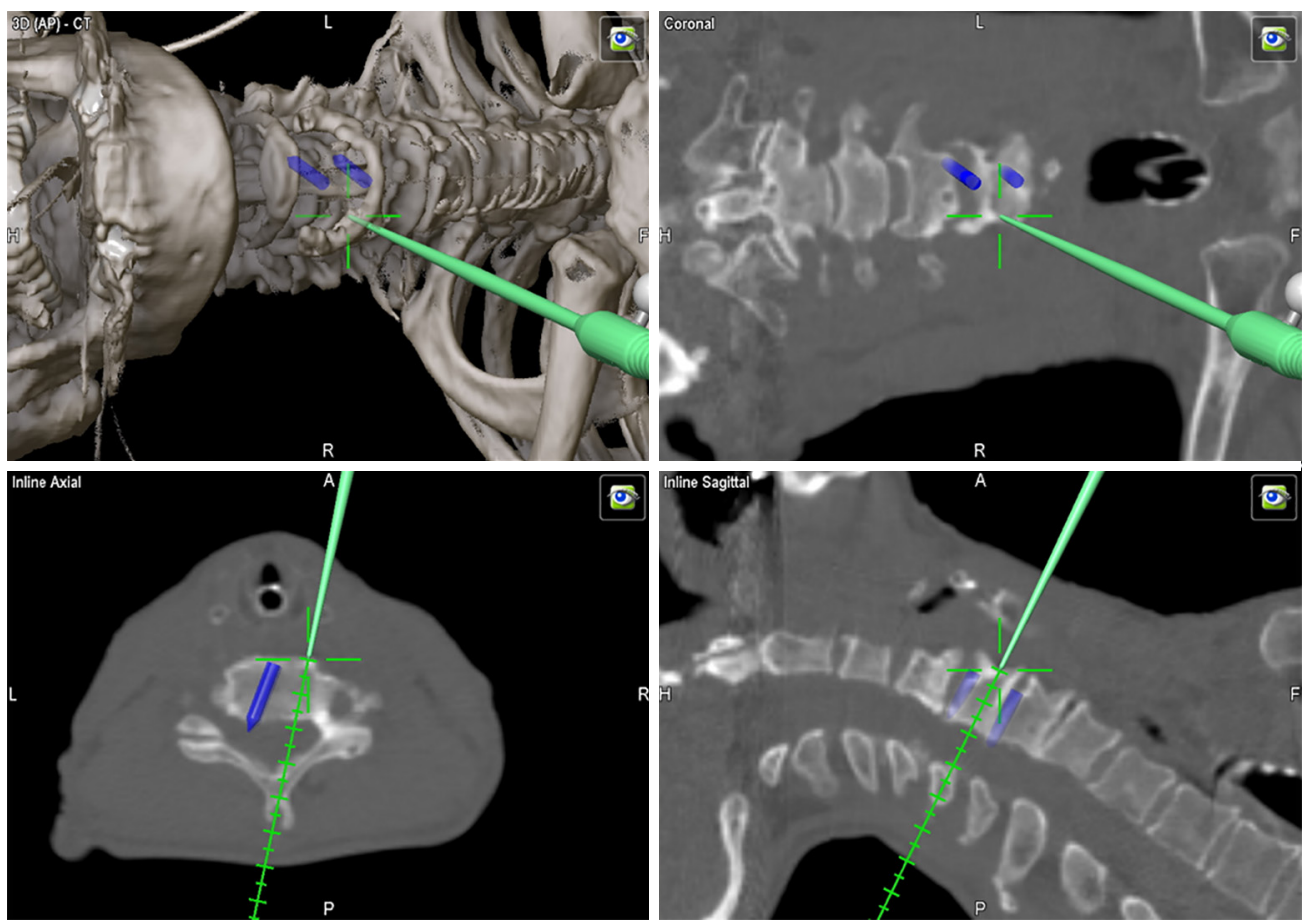

Figure 1 Intraoperative screenshots present a C5 corpectomy case. The lateral aspect of the corpectomy is confirmed with navigation. Blue virtual shapes are used to localize C4-5 and C5-6 disc spaces.

of the vertebral arteries via a preoperative CTA (31-34). In such cases, C1 lateral mass screws (LMS) together with C2 pedicle screws can be used for fixation, which was initially described by Goel et al. in 1994 (35) and modified by Harms et al. (36). using a polyaxial screw-rod construct in 2001. Moreover, in more recent studies, this technique also showed comparable outcomes to transarticular screws in terms of biomechanical stability (37).

Computer-assisted 3D navigation systems allows a more precise intraoperative image-guidance in atlantoaxial fixation surgery by improving the accuracy of screw placement, accelerating surgical workflow, and reducing intraoperative blood loss and radiation dose in comparison to the traditional fluoroscopy-guided surgical method (38-41). Yang et al. (42) reported that usage of intraoperative 3D navigation significantly decreased the screw breach rate, operative time, mean blood loss, and radiation time in comparison to the conventional $\mathrm{C}$-arm in patients who undergo a C1-2 fixation with Harms technique. In two other studies, both Hitti et al. (43) and Harel et al. (44) showed that utilization of $\mathrm{O}$-arm based intraoperative navigation reduced estimated blood loss by $50 \%$ in comparison to fluoroscopic guidance. On the other hand, similar improvements were observed with the utilization of intraoperative navigation for placement of C1-2 transarticular screws when Yang et al. demonstrated the superiority of the 3D C-arm over conventional fluoroscopy in terms of accuracy, estimated blood lost, and radiation time (45). More recently, Tian et al. reported a case in which they placed a unilateral C1-2 transarticular screw accurately without any complications with robotic guidance (46).

For the surgical procedure, the patient is placed in a prone position and the head is fixated on a Mayfield skull clamp. The reference array is attached to the head clamp. In cases that involve fractures, reduction must first be achieved by traction on each side and the appropriate alignment is then confirmed by lateral fluoroscopy. Once the posterior arches of $\mathrm{C} 1-\mathrm{C} 3$ are exposed, the navigation probe is used to determine the insertion point and craniocaudal/mediolateral direction of the transarticular screw which is aimed toward the upper half of the $\mathrm{C} 1$ anterior arch (Figure 2). When transarticular screws are placed percutaneously, the stab incision location and length can be planned accordingly using $3 \mathrm{D}$ navigation. Then an autologous bone graft harvested from the posterior iliac crest is placed between the $\mathrm{C} 1$ and $\mathrm{C} 2$ arches. If transarticular screws are 

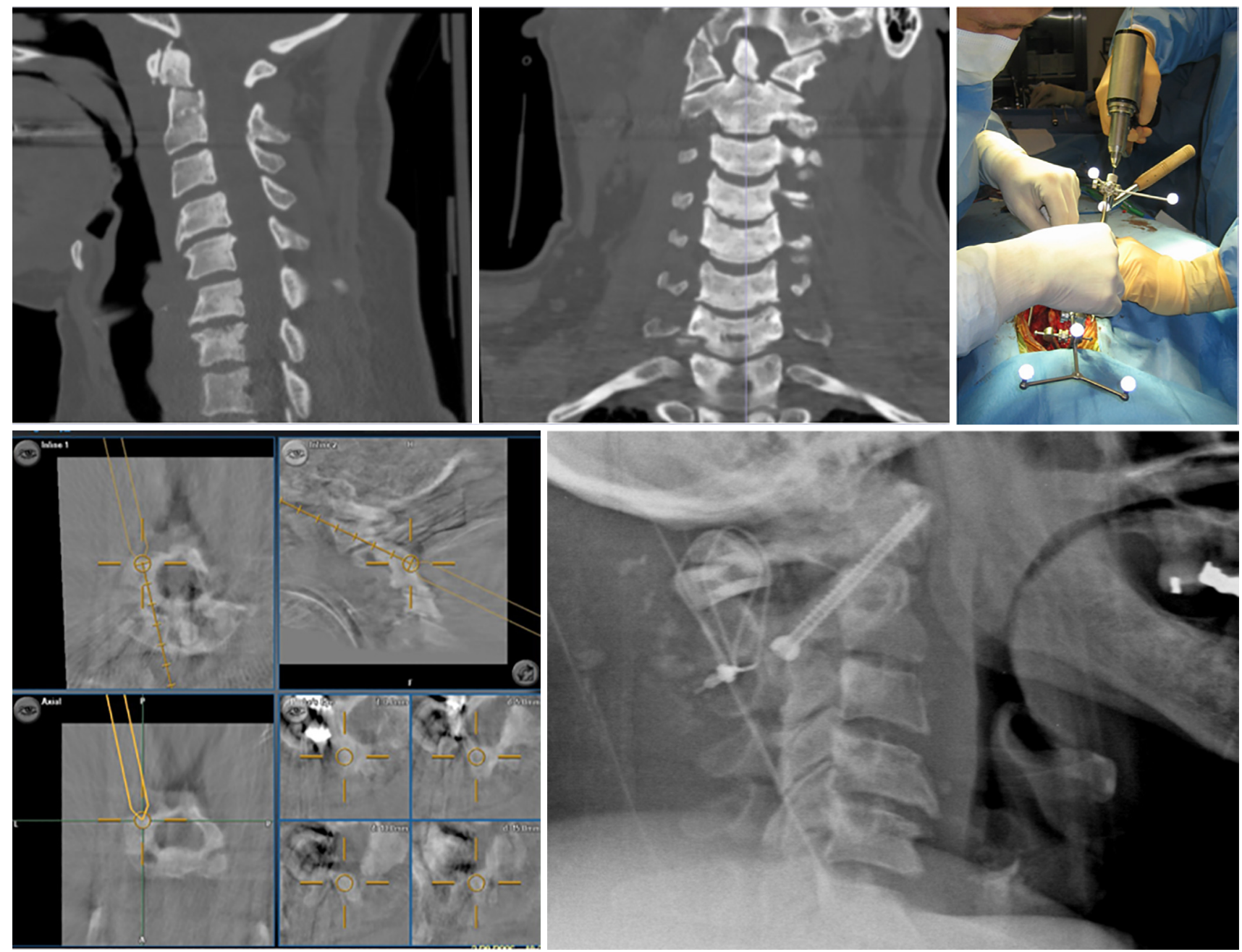

Figure 2 Transarticular C1/2 screw positioning with Magerl technique, the entry points as well as the screw trajectory is planned with intraoperative $3 \mathrm{D}$ navigation.

not feasible due to high riding transverse foramen or other anomalies of the vertebral artery, C1 LMS in combination with C2 pedicle/pars screws should be preferred (Figure 3).

\section{Subaxial cervical instrumentation}

\section{LMS}

LMS were first applied in subaxial cervical spine stabilization by Roy-Camille in 1964, leading to the replacement of pioneer wiring techniques (47). Over the next few years, many different modifications of this technique and their respective safety profiles were developed and shown (48-53). These techniques each have their own distinctive angulations, trajectories, and entry points, all of which are performed with fluoroscopic-guidance. The most common complications associated with LMS are vertebral artery injury, facet violation, or lateral mass fractures $(54,55)$. In order to decrease the risk of complications, the trajectory of LMS is usually aimed to be between 20 to 30 degrees laterally and cranially (53). Nevertheless, intraoperative 3D navigation eases the planning of the screw insertion point, trajectory, and even screw length (Figure 4). Arab et al. reported that the LMS malpositioning significantly decreased with intraoperative CT-based 3D navigation-guidance (56).

\section{Posterior cervical pedicle screws}

Pedicle screw fixation is considered the gold standard in lumbar and thoracic spine surgery; however, it has adapted slowly for use in the cervical spine due to barriers such as the smaller pedicle size and potential risk of 

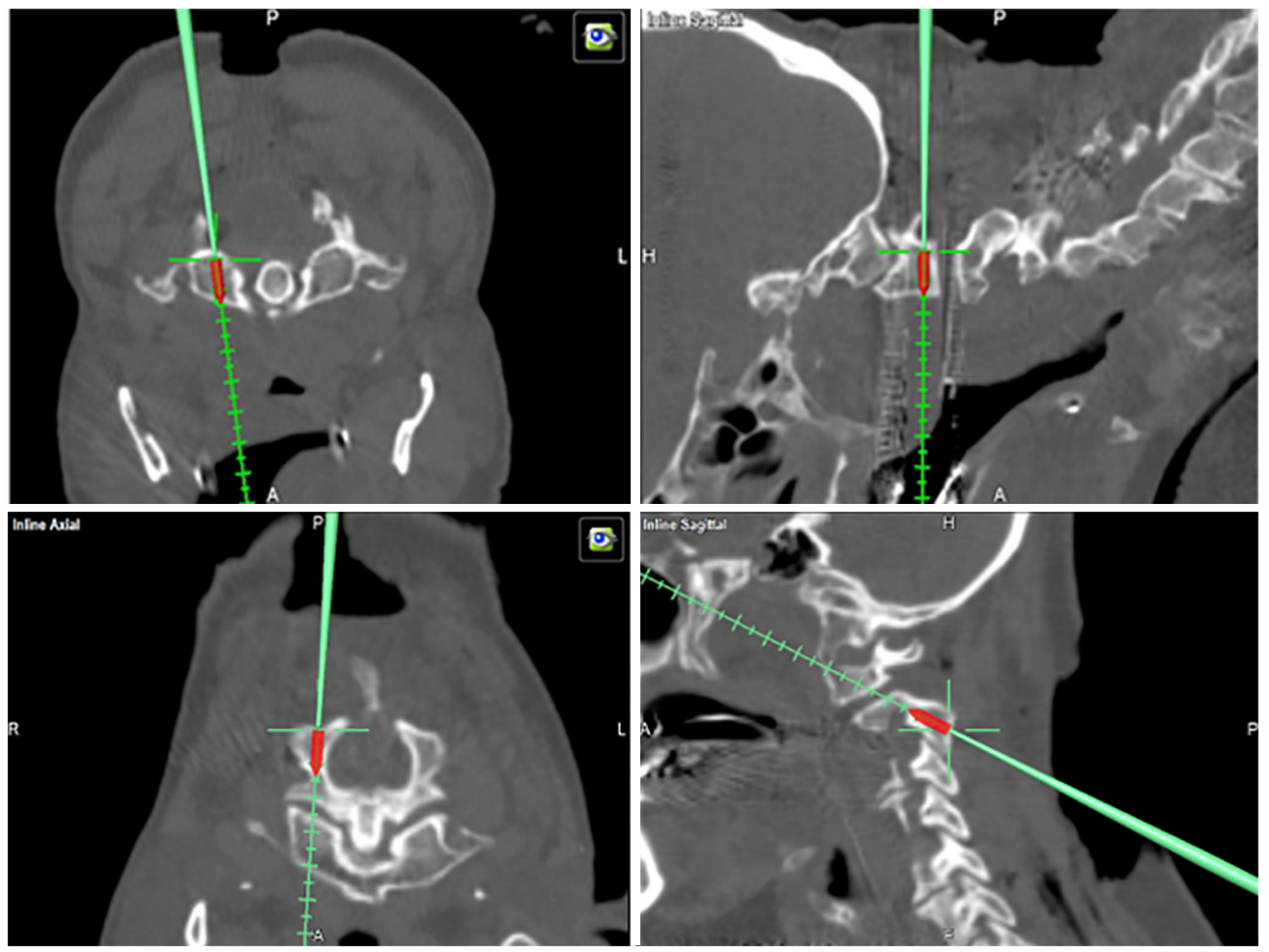

Figure 3 C1 lateral mass and C2 pars screws positioning with Harms technique, the entry points as well as the screw trajectory is planned with intraoperative $3 \mathrm{D}$ navigation.
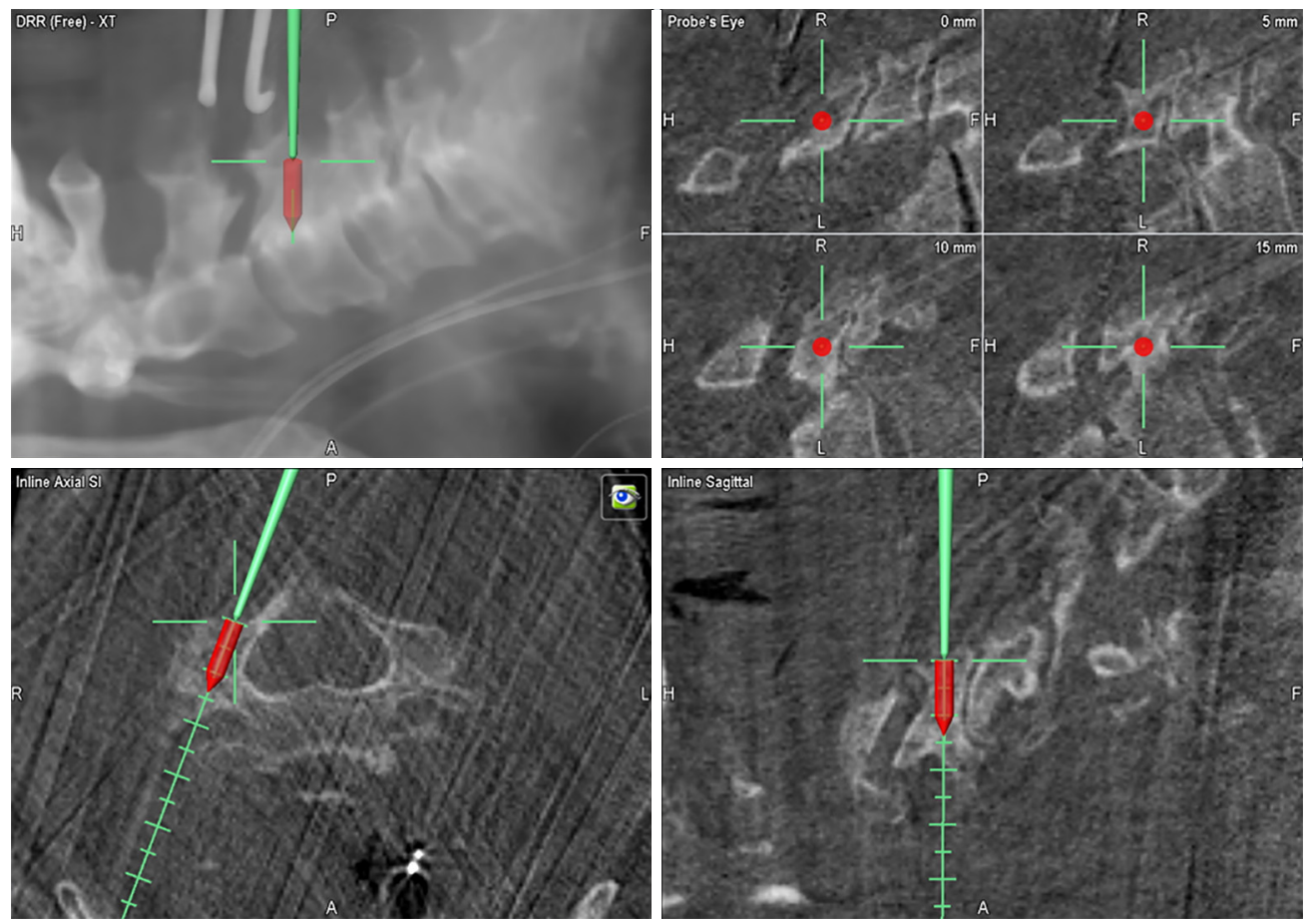

Figure 4 Intraoperative 3D navigation pictures showing the trajectory and position of the LMS. 

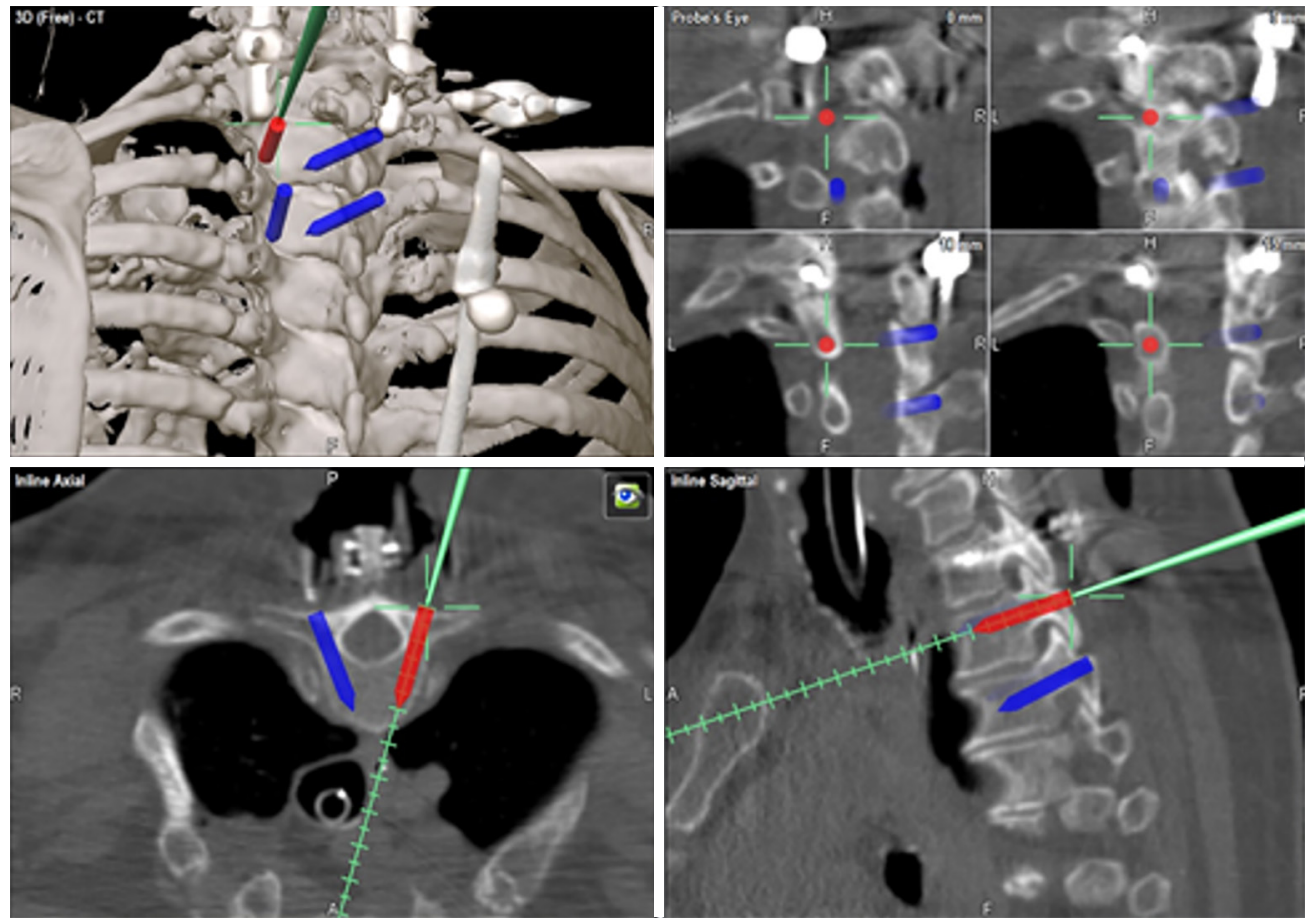

Figure 5 Pedicle screw placement in the lower cervical and upper thoracic spine with intraoperative 3D navigation.

injuring neighboring neuro-vascular structures (57-59). Nevertheless, it is demonstrated that cervical pedicle screws provide better biomechanical stability and stronger pullout strength than other fixation techniques and therefore, potentially require shorter instrumentation constructs (60-62). There is possible risk of neurovascular injury related to placement of the cervical pedicle screw, and vertebral artery injury is an especially noteworthy complication (63). The complication risk can be minimized by evaluating dimensions of the patients' pedicles and avoiding the application of this technique in non-suitable patients (20).

It has been shown that cervical pedicle screws can be placed safely and more accurately with navigation systems that determine entry points, angulations, and trajectories of the pedicle screws $(20,64-68)$. Several studies reported high misplacement rates from $6.7 \%$ to $29.1 \%$ with the conventional non-navigated cervical pedicle screw technique $(53,57,69-71)$. On the other hand, the literature reported perforation rates that ranged from $2 \%$ to $2.8 \%$ with $3 \mathrm{D}$ fluoroscopy-guidance $(65,67)$. Equivalent accuracy rates were shown by several surgeons who used intraoperative $\mathrm{O}$-arm based navigation systems $(64,66)$. In another study published by Shimokawa et al. (68) found higher accuracy rates with intraoperative $3 \mathrm{D}$ navigation in cervical and thoracic pedicle screw placement compared to preoperative CT-based systems (97.1\% vs. 93.6\%). The radiation exposure to the patient and OR staff during pedicle screw placement is another concern regarding intraoperative image guidance. Nottmeier et al. reported that the cervical anatomy can be visualized adequately and efficiently even for obese and osteoporotic patients when using the O-arm based intraoperative navigation system, reducing radiation exposure to patients by up to $40 \%$ (8).

From a technical perspective, the patient is positioned prone and the head is fixed using either a horse shoe or three-point cranial clamp. The reference array is usually placed on the spinous process, preferably in close proximity to the index levels. In cases in which the reference array is attached to Mayfield head-holder, the accuracy should be checked periodically. After the intraoperative scan is performed and images are uploaded, the entry points, screw trajectory, length, diameters, and incision line are planned in the axial, sagittal, and coronal planes with $3 \mathrm{D}$ navigation for percutaneous assisted cannulated screw placement $(72,73)$ (Figure 5). This step plays a key role in reducing the risks of screw pullout and breaches by optimizing the outer diameter and length of the screw in relation to the inner diameter of the pedicle (74-76). A high-speed drill is usually 
used for preparation of the pilot holes for pedicle screw insertion. The use of the drill allows surgeons to understand the bony resistance and minimizes antero-posterior forces during the creation of pilot holes. Next, the pedicle screws are tapped and the accuracy is confirmed by the navigation probe. Laminectomy should be performed at the end if it is indicated, as the bony lamina can serve as a protective barrier to the dura during instrumentation.

\section{Percutaneous interfacet cage implantation}

Cervical facet joint distraction was initially described by Goel et al. for the treatment of basilar invagination in early 2000s (77) and later, this technique was used to achieve indirect decompression for single-level cervical radiculopathy/myelopathy (78-81). More recently, minimally invasive percutaneous interfacet cage implants (e.g., DTRAX; Providence Medical Technology, Inc., Pleasanton, CA) have become alternatives to traditional open posterior cervical fusion with LMS (82-84). This technology is mainly indicated for foraminal stenosis, facet mediated pain, pseudoarthrosis, and adjacent level compromise following a prior ACDF. In a cadaveric study, Voronov et al. (85) demonstrated that bilateral interfacet cages can provide comparable segmental stability to posterior cervical fusion with LMS. Siemionow et al. performed postoperative radiographic analysis on patients who underwent posterior cervical fusion using bilateral interfacet cages to demonstrate bilateral interfacet cages can increase foraminal area (83). McCormack et al. reported that significant improvement in clinical outcomes up to one year after percutaneous posterior cervical fusion with interfacet cages (82). Interfacet cage implantation can be a safe alternative to other cervical spinal fusion surgeries with a favorable complication profile $(84,86)$. To date, there is no data available on the use of $3 \mathrm{D}$ navigation for interfacet cage implantations.

For the surgical procedure, the patient is placed in the prone position and attached to a Mayfield head holder. During this procedure, SSEP and MEP neuromonitoring should be utilized. Although fluoroscopy alone can be used, $3 \mathrm{D}$-navigation can facilitate implant placement due to its ability to visualize the trajectory in the coronal, axial, and sagittal planes. 3D-navigation is used to identify both the media and lateral aspect of the facet (Figure 6) (87). The procedure begins with the insertion of the guide tube. In order to avoid damage to the nerve root, the access chisel should enter the joint following a medial to lateral trajectory similar to cervical lateral mass screw placement and also, remain collinear to the joint. A pineapple tipped decorticating burr is used to ream out the inside of the facet joint. Once the burr is removed, a cage with bone graft is inserted via the guide tube and bone screws are used to fixate it into the inferior articulating facet. All instruments except the guide tube is removed. Then, additional bone graft material is added onto the joint via the guide tube. Finally, the guide tube is removed and the wound is irrigated and closed in a routine fashion.

\section{PCF}

PCF is a well-established surgical technique among operative treatments for unilateral radiculopathy (88-90). This technique was initially described in the 1940s $(91,92)$ and later, its minimally invasive modifications were developed by adapting tubular retractors and endoscopes $(93,94)$. It has been shown that PCF has comparable clinical outcomes with conventional ACDF for the treatment of unilateral cervical radiculopathy while the risk of complications including dysphagia, recurrent laryngeal nerve injury, and adjacent segment disease is significantly reduced (95-97). The risk of requiring a revision fusion at the index level for patients undergoing PCF ranged from $1.1 \%$ to $5 \%$ in the literature $(98,99)$. Moreover, minimally invasive PCF has several advantages over the traditional open technique in terms of blood loss, operation times, inpatient analgesic use, and length of hospital stays $(93,100)$. However, certain difficulties exist when performing a minimally-invasive PCF due to the limited visibility provided through a tubular retractor, and can be even more challenging in the lower cervical spine and C-T junction of obese patients with short and thick necks (100). Herein, the use of 3D navigation-guidance facilitates the surgical workflow, assists in deciding the boundaries of foraminotomy, and allows a safe and efficacious decompression at the intended level $(87,101)$. Similarly, 3D navigation enables surgeons to perform a safe and efficient full endoscopic PCF where it provides great accuracy and helps to overcome the limited vision under the endoscope (102).

For the surgical procedure, the patient is placed in a prone position with rigid head fixation and the reference array is attached to either a skull clamp head-holder or over the cervicothoracic junction. A 2-cm paramedian incision is then made in the skin and cervical fascia, of which is planned via $3 \mathrm{D}$ navigation-guidance. In general, a $14-$ or $16-\mathrm{mm}$ tubular retractor is docked following the serial insertion of sequential dilators. The accuracy of intraoperative 

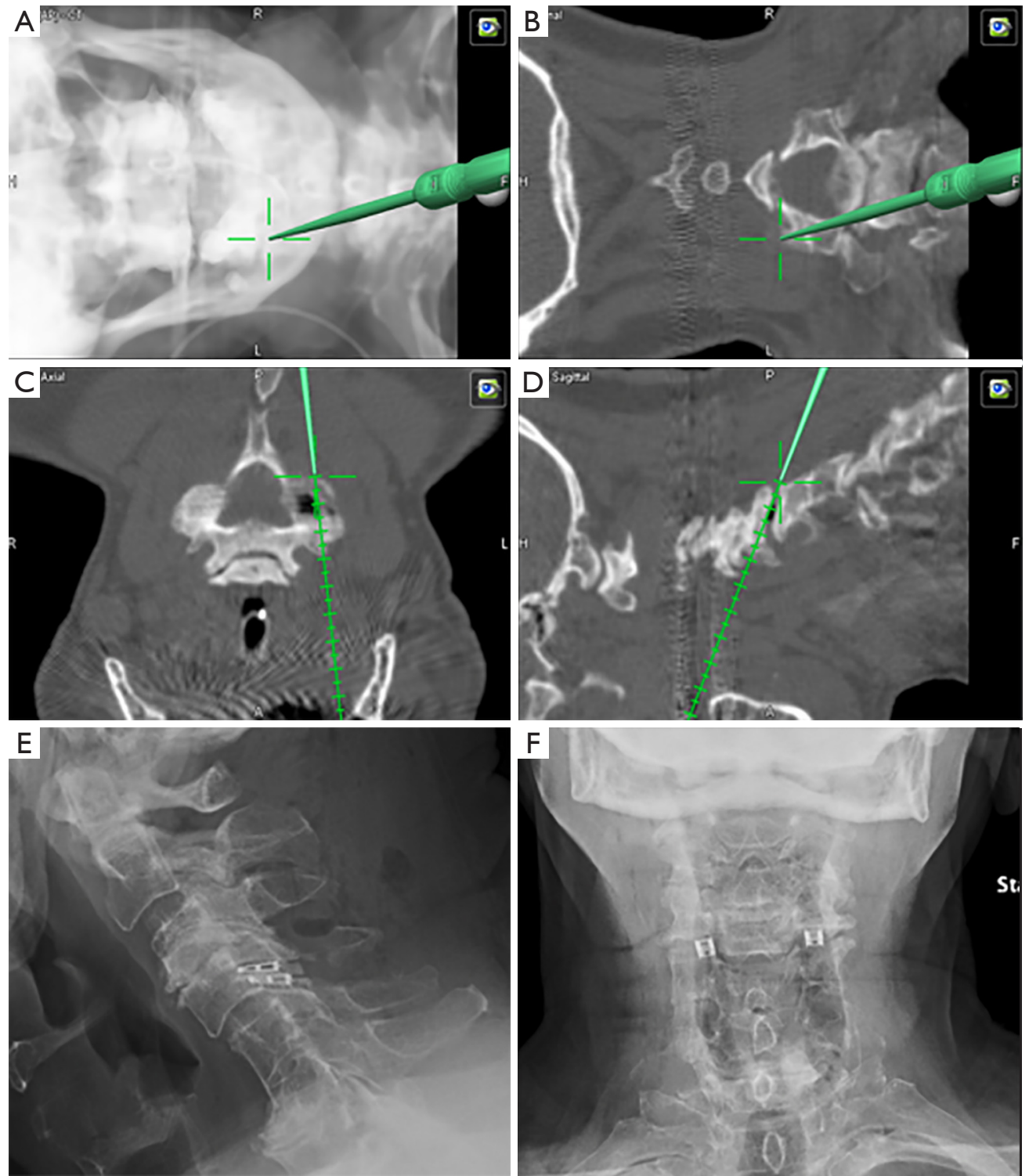

Figure 6 Intraoperative 3D navigation screenshots demonstrating the trajectory and ultimate target of the interfacet joint cage (A,B,C,D). Postoperative (E) lateral and (F) anteroposterior radiographs following bilateral interfacet joint cage implantation. With permission of ref. (87).

navigation should be confirmed at this point and then, the shape and extent of the foraminotomy can be decided (Figure 7). Typically, bone drilling begins at the V-point (the lateral aspect of the superior and inferior hemilamina and medial third of the facet joint) using a high-speed burr. Data suggests that removing greater than $50 \%$ of the facet joint should be avoided since it can cause segmental hypermobility $(103,104)$. Then, Kerrison rongeurs are used to remove the ligamentum flavum and widen the foraminotomy. At this point, the lateral edge of the dural sac as well as the branching nerve root are identified, and nerve hooks are used to retract the exiting nerve while the discectomy is completed using micropituitary rongeurs. In the end, the navigation probe is used to ensure achievement of sufficient decompression.

\section{Cervical unilateral laminotomy for bilateral decompression}

In 1997, Spetzger et al. introduced the "unilateral laminotomy for bilateral decompression" (ULBD) 

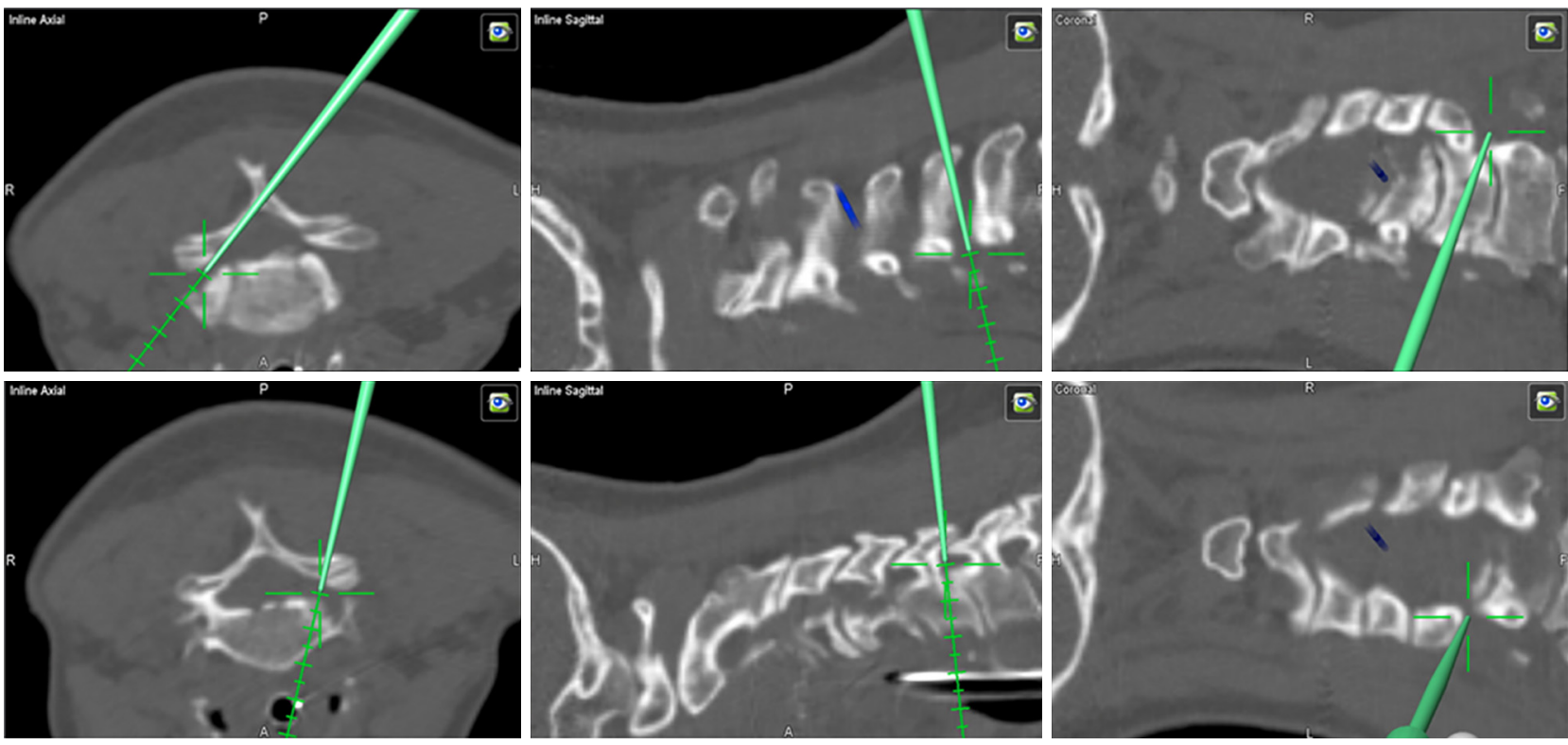

Figure 7 Intraoperative 3D navigation pictures presenting a PCF case. With permission of ref. (87).

technique for lumbar spinal stenosis (105). In following years, this surgical concept has been adapted for treatment of cervical spine and has become one of the main principles of minimally invasive spine surgery (106). Although there are various treatment options for cervical spondylotic myelopathy, each procedure has both advantages and disadvantages associated with manipulation. The conventional laminectomy-alone may contribute to a late cervical kyphotic deformity, late neurologic deterioration and postoperative axial symptoms (107-109). Minimally invasive cervical ULBD can be a better alternative to open the laminectomy for treatment of single or multilevel cervical spondylotic myelopathy $(110,111)$ (Figure 8). Although the literature lacks the data comparing open cervical laminotomy to minimally ULBD, Minamide et al. reported that endoscopic ULBD demonstrated similar neurological outcomes with maintaining sagittal alignment and less axial symptoms compared to open cervical laminoplasty in their 5 -year cohort study (112).

The technical aspect of the procedure involves positioning the patient prone with the head immobilized in a 3-pin skull clamp with the reference array attached. The incision site is determined based on total $3 \mathrm{D}$ navigation and then, a $2.5-\mathrm{cm}$ incision is made approximately $2 \mathrm{~cm}$ off the midline. After incising the fascia, the first dilator is then passed through the created plane to dock onto the lamina and subsequently, serial dilation is performed. Later, a 16-
$18 \mathrm{~mm}$ tubular retractor is placed and the triangle formed by the lamino-facet junction is identified with the assistance of the pointer. The bony removal begins at the inferior aspect of the cranial lamina using a combination of a highspeed drill and Kerrison ronguers until the cranial insertion of the ligamentum flavum is reached, often indicated by the epidural fat. Next, the superior aspect of the caudal lamina is drilled away. Following this step, the tubular retractor should be tilted to aim medially and the operating table should be rotated away from the surgeon to grant the surgeon an appropriate trajectory for the performance of the contralateral decompression, undercutting the spinous process. The ventral surface of the contralateral lamina is drilled away without removing the ligament flavum to protect the spinal cord. At this point, it's important to avoid applying downward pressure on the spinal cord. Once the ligamentum flavum has been mobilized away from its attachments, Kerrison rongeurs are used for removal of the ligamentum flavum. Finally, the adequate decompression in the contralateral side is confirmed using $3 \mathrm{D}$ navigationguidance (Figure 9).

\section{Conclusions}

The introduction of navigation and intraoperative imageguidance revolutionized spine surgery and provided great benefits particularly for minimally invasive approaches. 

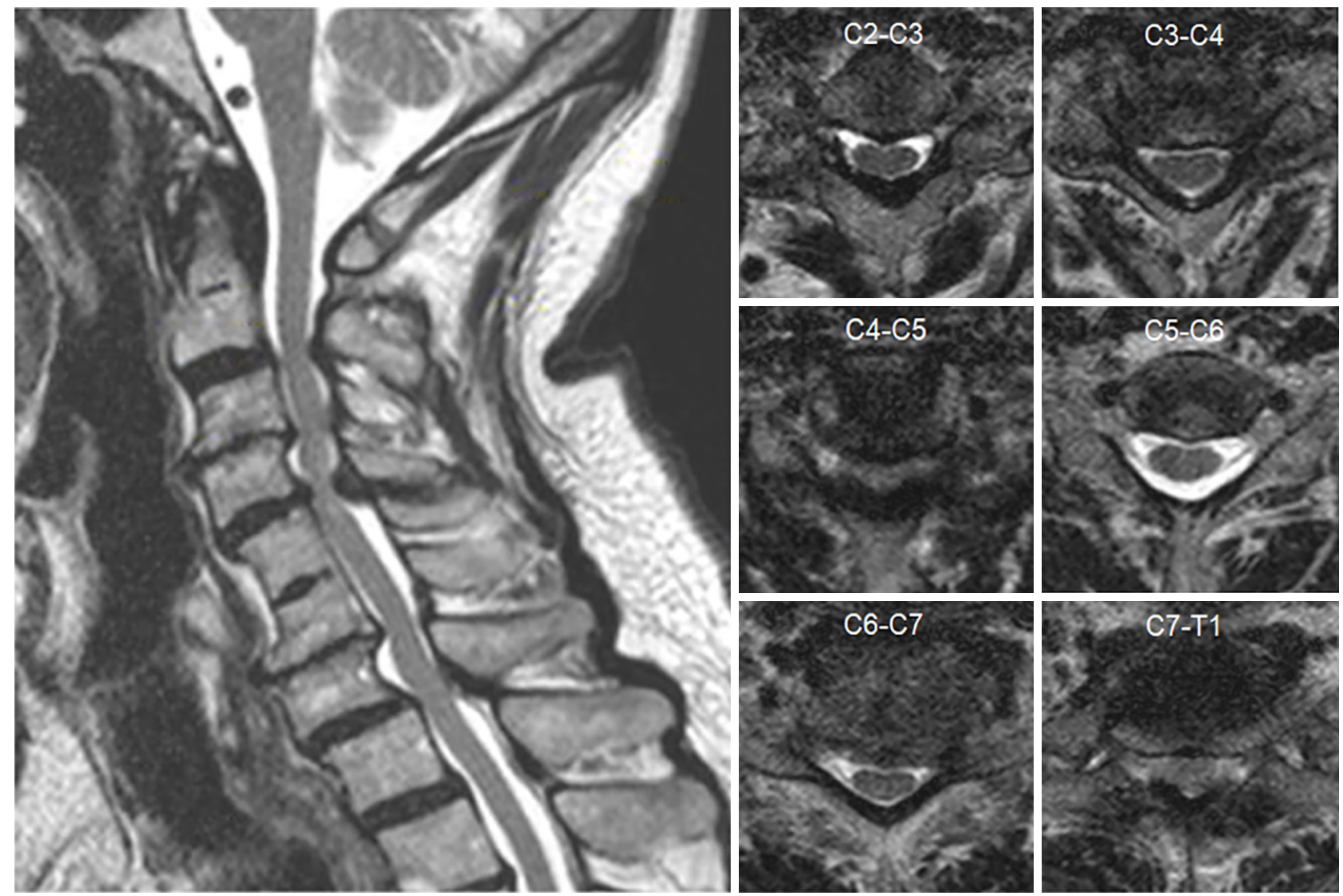

Figure 8 Multi-level cervical disc disease and spinal canal stenosis. With permission of ref. (87).
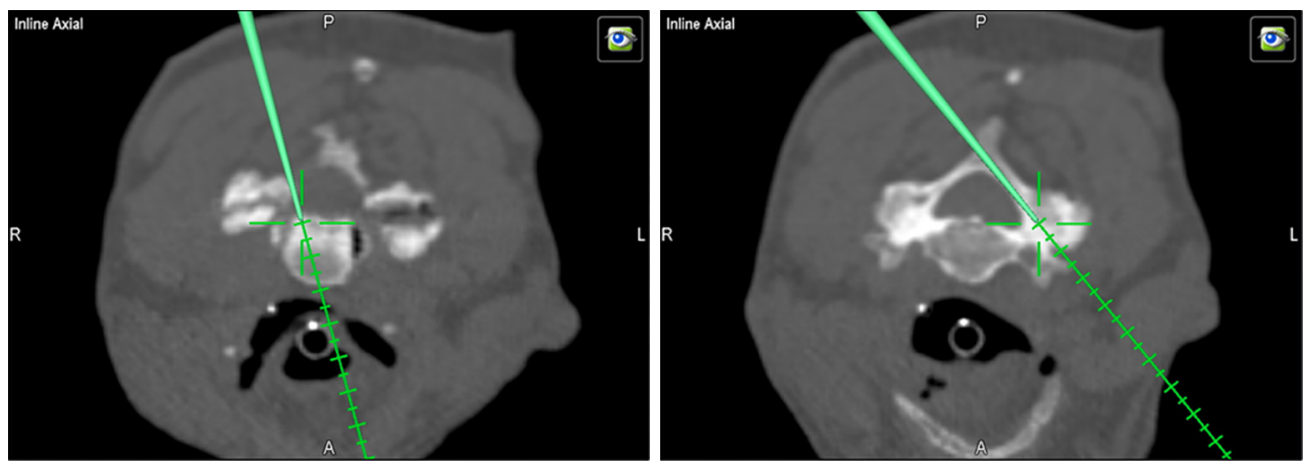

Figure 9 Unilateral laminotomy for “over the top” bilateral decompression. Intraoperative 3D navigation facilitates adequate contralateral decompression. With permission of ref. (87).

Although the intraoperative navigation is more commonly used in thoracolumbar spine surgery, it has rapidly gained popularity in cervical approaches. Placement of the reference array remains the primary limitation of navigation systems in the cervical spine. Literature suggested that the use of $3 \mathrm{D}$ navigation significantly reduces the screw malposition, operative time, mean blood loss, radiation exposure, and complication rates in comparison to the conventional fluoroscopic-guidance. Although 3D navigation has potential to replace conventional fluoroscopy, further evidence is needed to establish the superiority of navigation over conventional fluoroscopy in specific 
procedures for cervical spine.

\section{Acknowledgments}

Funding: None.

\section{Footnote}

Provenance and Peer Review: This article was commissioned by the Guest Editor (Dr. Sheeraz Qureshi) for the series "Current State of Intraoperative Imaging" published in Annals of Translational Medicine. The article was sent for external peer review organized by the Guest Editor and the editorial office.

Conflicts of Interest: All authors have completed the ICMJE uniform disclosure form (available at http://dx.doi. org/10.21037/atm-20-1101). The series "Current State of Intraoperative Imaging" was commissioned by the editorial office without any funding or sponsorship. RH reports that he is a consultant for Ulrich, Brainlab, DePuy-Synthes and he has royalties from Zimmer. The authors have no other conflicts of interest to declare.

Ethical Statement: The authors are accountable for all aspects of the work in ensuring that questions related to the accuracy or integrity of any part of the work are appropriately investigated and resolved.

Open Access Statement: This is an Open Access article distributed in accordance with the Creative Commons Attribution-NonCommercial-NoDerivs 4.0 International License (CC BY-NC-ND 4.0), which permits the noncommercial replication and distribution of the article with the strict proviso that no changes or edits are made and the original work is properly cited (including links to both the formal publication through the relevant DOI and the license). See: https://creativecommons.org/licenses/by-nc-nd/4.0/.

\section{References}

1. Holly LT, Foley KT. Image guidance in spine surgery. Orthop Clin North Am 2007;38:451-61; abstract viii.

2. Mezger $U$, Jendrewski C, Bartels M. Navigation in surgery. Langenbecks Arch Surg 2013;398:501-14.

3. Navarro-Ramirez R, Lang G, Lian X, et al. Total Navigation in Spine Surgery; A Concise Guide to Eliminate Fluoroscopy Using a Portable Intraoperative
Computed Tomography 3-Dimensional Navigation System. World Neurosurg 2017;100:325-35.

4. Kirnaz S, Navarro-Ramirez R, Wipplinger C, et al. Minimally Invasive Transforaminal Lumbar Interbody Fusion using 3-Dimensional Total Navigation: 2-Dimensional Operative Video. Oper Neurosurg (Hagerstown) 2020;18:E9-10.

5. Kirnaz S, Wipplinger C, Schmidt FA, et al. Minimally Invasive Laminotomy for Contralateral "Over-theTop" Foraminal Decompression Using 3-Dimensional Total Navigation: 2-Dimensional Operative Video. Oper Neurosurg (Hagerstown) 2019. doi: 10.1093/ons/opz399.

6. Moses ZB, Mayer RR, Strickland BA, et al. Neuronavigation in minimally invasive spine surgery. Neurosurg Focus 2013;35:E12.

7. Pirris SM, Nottmeier EW. A case series on the technical use of three-dimensional image guidance in subaxial anterior cervical surgery. Int J Med Robot 2015;11:44-51.

8. Nottmeier EW, Pirris SM, Edwards S, et al. Operating room radiation exposure in cone beam computed tomography-based, image-guided spinal surgery. 2013;19:226.

9. Smith GW, Robinson RA. The treatment of certain cervical-spine disorders by anterior removal of the intervertebral disc and interbody fusion. J Bone Joint Surg Am 1958;40-a:607-24.

10. Cloward RB. The anterior approach for removal of ruptured cervical disks. J Neurosurg 1958;15:602-17.

11. Fraser JF, Hartl R. Anterior approaches to fusion of the cervical spine: a metaanalysis of fusion rates. J Neurosurg Spine 2007;6:298-303.

12. Song KJ, Taghavi CE, Lee KB, et al. The efficacy of plate construct augmentation versus cage alone in anterior cervical fusion. Spine (Phila Pa 1976) 2009;34:2886-92.

13. Yao N, Wang C, Wang W, et al. Full-endoscopic technique for anterior cervical discectomy and interbody fusion: 5 -year follow-up results of 67 cases. Eur Spine J 2011;20:899-904.

14. Ruetten S, Komp M, Merk H, et al. Full-endoscopic anterior decompression versus conventional anterior decompression and fusion in cervical disc herniations. Int Orthop 2009;33:1677-82.

15. Kim JS, Eun SS, Prada N, et al. Modified transcorporeal anterior cervical microforaminotomy assisted by $\mathrm{O}$-armbased navigation: a technical case report. Eur Spine J 2011;20:S147-52.

16. Skovrlj B, Qureshi SA. Minimally invasive cervical spine surgery. J Neurosurg Sci 2017;61:325-34. 
17. Rizk A, Ottenbacher A. Image-Guided Navigation in Anterior Cervical Spine Surgery using a Cranial Frame. Egyptian Spine Journal 2019;29:56-65.

18. Jang SH, Cho JY, Choi WC, et al. Novel method for setting up 3D navigation system with skin-fixed dynamic reference frame in anterior cervical surgery. Comput Aided Surg 2015;20:24-8.

19. Rahmathulla G, Nottmeier EW, Pirris SM, et al. Intraoperative image-guided spinal navigation: technical pitfalls and their avoidance. Neurosurg Focus 2014;36:E3.

20. Bredow J, Oppermann J, Kraus B, et al. The accuracy of $3 \mathrm{D}$ fluoroscopy-navigated screw insertion in the upper and subaxial cervical spine. Eur Spine J 2015;24:2967-76.

21. Patton AG, Morris RP, Kuo YF, et al. Accuracy of fluoroscopy versus computer-assisted navigation for the placement of anterior cervidcal pedicle screws. Spine (Phila Pa 1976) 2015;40:E404-10.

22. Bredow J, Meyer C, Siedek F, et al. Accuracy of 3D fluoronavigated anterior transpedecular screws in the subaxial cervical spine: an experimental study on human specimens. Eur Spine J 2017;26:2934-40.

23. Offiah CE, Day E. The craniocervical junction: embryology, anatomy, biomechanics and imaging in blunt trauma. Insights Imaging 2017;8:29-47.

24. Stock GH, Vaccaro AR, Brown AK, et al. Contemporary posterior occipital fixation. J Bone Joint Surg Am 2006;88:1642-9.

25. Grob D, Dvorak J, Panjabi M, et al. Posterior occipitocervical fusion. A preliminary report of a new technique. Spine (Phila Pa 1976) 1991;16:S17-24.

26. Gallie WE. Fractures and dislocations of the cervical spine. Am J Surg 1939:495-9.

27. Brooks AL, Jenkins EB. Atlanto-axial arthrodesis by the wedge compression method. J Bone Joint Surg Am 1978;60:279-84.

28. Dickman CA, Sonntag VK, Papadopoulos SM, et al. The interspinous method of posterior atlantoaxial arthrodesis. J Neurosurg 1991;74:190-8.

29. Magerl F, Seemann P-S. Stable Posterior Fusion of the Atlas and Axis by Transarticular Screw Fixation. In: Kehr P, Weidner A, editors. Cervical Spine I: Strasbourg 1985. Vienna: Springer, 1987:322-7.

30. Richter M, Schmidt R, Claes L, et al. Posterior atlantoaxial fixation: biomechanical in vitro comparison of six different techniques. Spine (Phila Pa 1976) 2002;27:1724-32.

31. Paramore CG, Dickman CA, Sonntag VK. The anatomical suitability of the C1-2 complex for transarticular screw fixation. J Neurosurg 1996;85:221-4.
32. Tian W, Liu Y, Zheng S, et al. Accuracy of lower cervical pedicle screw placement with assistance of distinct navigation systems: a human cadaveric study. Eur Spine J 2013;22:148-55.

33. Ishak B, Schneider T, Gimmy V, et al. Early Complications, Morbidity, and Mortality in Octogenarians and Nonagenarians Undergoing Posterior IntraOperative Spinal Navigation-Based C1/2 Fusion for Type II Odontoid Process Fractures. J Neurotrauma 2017;34:3326-35.

34. Jacobs C, Roessler PP, Scheidt S, et al. When does intraoperative 3D-imaging play a role in transpedicular $\mathrm{C} 2$ screw placement? Injury 2017;48:2522-8.

35. Goel A, Laheri V. Plate and screw fixation for atlanto-axial subluxation. Acta Neurochir (Wien) 1994;129:47-53.

36. Harms J, Melcher RP. Posterior C1-C2 fusion with polyaxial screw and rod fixation. Spine (Phila Pa 1976) 2001;26:2467-71.

37. Park J, Scheer JK, Lim TJ, et al. Biomechanical analysis of Goel technique for C1-2 fusion. J Neurosurg Spine 2011;14:639-46.

38. Czabanka M, Haemmerli J, Hecht N, et al. Spinal navigation for posterior instrumentation of C1-2 instability using a mobile intraoperative CT scanner. J Neurosurg Spine 2017;27:268-75.

39. Ould-Slimane M, Ferracci FX, Le Pape S, et al. Posterior C1C2 harms fusion with 3D surgical navigation. Orthop Traumatol Surg Res 2018;104:585-8.

40. Fiorenza V, Ascanio F. Safety and Efficacy of Posterior Atlanto-Axial Stabilization Using Intraoperative Navigation System with Preoperative Computed Tomographic Scan. World Neurosurg 2019;129:110-9.

41. Costa F, Ortolina A, Attuati L, et al. Management of C1-2 traumatic fractures using an intraoperative 3D imaging-based navigation system. J Neurosurg Spine 2015;22:128-33.

42. Yang YL, Zhou DS, He JL. Comparison of isocentric $\mathrm{C}$-arm 3-dimensional navigation and conventional fluoroscopy for C1 lateral mass and C2 pedicle screw placement for atlantoaxial instability. J Spinal Disord Tech 2013;26:127-34.

43. Hitti FL, Hudgins ED, Chen HI, et al. Intraoperative Navigation Is Associated with Reduced Blood Loss During C1-C2 Posterior Cervical Fixation. World Neurosurg 2017;107:574-8.

44. Harel R, Nulman M, Knoller N. Intraoperative imaging and navigation for C1-C2 posterior fusion. Surg Neurol Int 2019;10:149. 
45. Yang $\mathrm{Y}$, Wang F, Han S, et al. Isocentric C-arm threedimensional navigation versus conventional $\mathrm{C}$-arm assisted C1-C2 transarticular screw fixation for atlantoaxial instability. Arch Orthop Trauma Surg 2015;135:1083-92.

46. Tian W. Robot-Assisted Posterior C1-2 Transarticular Screw Fixation for Atlantoaxial Instability: A Case Report. Spine (Phila Pa 1976) 2016;41 Suppl 19:B2-5.

47. Roy-Camille R GG, Bertreaux D. Early management of spinal injuries. In: B M, editor. Recent Advances in Orthopedics. Edinburgh: Churchill-Livingstone, 1979:57-87.

48. An HS, Coppes MA. Posterior cervical fixation for fracture and degenerative disc disease. Clin Orthop Relat Res 1997:101-11.

49. An HS, Gordin R, Renner K. Anatomic considerations for plate-screw fixation of the cervical spine. Spine (Phila $\mathrm{Pa}$ 1976) 1991;16:S548-51.

50. Anderson PA, Henley MB, Grady MS, et al. Posterior cervical arthrodesis with $\mathrm{AO}$ reconstruction plates and bone graft. Spine (Phila Pa 1976) 1991;16:S72-9.

51. Jeanneret B, Magerl F, Ward EH, et al. Posterior stabilization of the cervical spine with hook plates. Spine (Phila Pa 1976) 1991;16:S56-63.

52. Nazarian SM, Louis RP. Posterior internal fixation with screw plates in traumatic lesions of the cervical spine. Spine (Phila Pa 1976) 1991;16:S64-71.

53. Joaquim AF, Mudo ML, Tan LA, et al. Posterior Subaxial Cervical Spine Screw Fixation: A Review of Techniques. Global Spine J 2018;8:751-60.

54. Heller JG, Silcox DH, 3rd, Sutterlin CE, 3rd. Complications of posterior cervical plating. Spine (Phila Pa 1976) 1995;20:2442-8.

55. Inoue $\mathrm{S}$, Moriyama T, Tachibana T, et al. Cervical lateral mass screw fixation without fluoroscopic control: analysis of risk factors for complications associated with screw insertion. Arch Orthop Trauma Surg 2012;132:947-53.

56. Arab A, Alkherayf F, Sachs A, et al. Use of 3D Navigation in Subaxial Cervical Spine Lateral Mass Screw Insertion. J Neurol Surg Rep 2018;79:e1-e8.

57. Abumi K, Shono Y, Kotani Y, et al. Indirect posterior reduction and fusion of the traumatic herniated disc by using a cervical pedicle screw system. J Neurosurg 2000;92:30-7.

58. Abumi K, Kaneda K. Pedicle screw fixation for nontraumatic lesions of the cervical spine. Spine (Phila $\mathrm{Pa}$ 1976) 1997;22:1853-63.

59. Ludwig SC, Kramer DL, Vaccaro AR, et al. Transpedicle screw fixation of the cervical spine. Clin Orthop Relat Res 1999:77-88.
60. Dunlap BJ, Karaikovic EE, Park HS, et al. Load sharing properties of cervical pedicle screw-rod constructs versus lateral mass screw-rod constructs. Eur Spine J 2010;19:803-8.

61. Barnes AH, Eguizabal JA, Acosta FL, Jr., et al. Biomechanical pullout strength and stability of the cervical artificial pedicle screw. Spine (Phila Pa 1976) 2009;34:E16-20.

62. Jones EL, Heller JG, Silcox DH, et al. Cervical pedicle screws versus lateral mass screws. Anatomic feasibility and biomechanical comparison. Spine (Phila $\mathrm{Pa} 1976)$ 1997;22:977-82.

63. Yoshihara H, Passias PG, Errico TJ. Screw-related complication in the subaxial cervical spine with the use of lateral mass versus cervical pedicle screws: a systematic review. J Neurosurg Spine 2013:19:614-23.

64. Chachan S, Bin Abd Razak HR, Loo WL, et al. Cervical pedicle screw instrumentation is more reliable with $\mathrm{O}$-armbased 3D navigation: analysis of cervical pedicle screw placement accuracy with $\mathrm{O}$-arm-based 3D navigation. Eur Spine J 2018;27:2729-36.

65. Hott JS, Deshmukh VR, Klopfenstein JD, et al. Intraoperative Iso-C C-arm navigation in craniospinal surgery: the first 60 cases. Neurosurgery 2004;54:1131-6; discussion 1136-7.

66. Ishikawa Y, Kanemura T, Yoshida G, et al. Intraoperative, full-rotation, three-dimensional image (O-arm)-based navigation system for cervical pedicle screw insertion. J Neurosurg Spine 2011;15:472-8.

67. Ito Y, Sugimoto Y, Tomioka M, et al. Clinical accuracy of 3D fluoroscopy-assisted cervical pedicle screw insertion. J Neurosurg Spine 2008;9:450-3.

68. Shimokawa N, Takami T. Surgical safety of cervical pedicle screw placement with computer navigation system. Neurosurg Rev 2017;40:251-8.

69. Neo M, Sakamoto T, Fujibayashi S, et al. The clinical risk of vertebral artery injury from cervical pedicle screws inserted in degenerative vertebrae. Spine (Phila $\mathrm{Pa}$ 1976) 2005;30:2800-5.

70. Kosmopoulos V, Schizas C. Pedicle screw placement accuracy: a meta-analysis. Spine (Phila Pa 1976) 2007;32:E111-20.

71. Urbanski $W$, Jurasz $W$, Wolanczyk $M$, et al. Increased Radiation but No Benefits in Pedicle Screw Accuracy With Navigation versus a Freehand Technique in Scoliosis Surgery. Clin Orthop Relat Res 2018;476:1020-7.

72. Richter M, Ploux D. Spinale Navigation zur dorsalen zervikalen und zervikothorakalen Instrumentierung. 
Operative Orthopädie und Traumatologie 2019;31:263-74.

73. Richter M, Cakir B, Schmidt R. Cervical pedicle screws: conventional versus computer-assisted placement of cannulated screws. Spine (Phila Pa 1976) 2005;30:2280-7.

74. Chapman JR, Harrington RM, Lee KM, et al. Factors affecting the pullout strength of cancellous bone screws. J Biomech Eng 1996;118:391-8.

75. Cho W, Cho SK, Wu C. The biomechanics of pedicle screw-based instrumentation. J Bone Joint Surg Br 2010;92:1061-5.

76. Hirano T, Hasegawa K, Takahashi HE, et al. Structural characteristics of the pedicle and its role in screw stability. Spine (Phila Pa 1976) 1997;22:2504-9; discussion 2510.

77. Goel A. Treatment of basilar invagination by atlantoaxial joint distraction and direct lateral mass fixation. J Neurosurg Spine 2004;1:281-6.

78. Goel A. Interfacetal intra-articular spacers: Emergence of a concept. J Craniovertebr Junction Spine 2016;7:72-4.

79. Goel A. Facet distraction spacers for treatment of degenerative disease of the spine: Rationale and an alternative hypothesis of spinal degeneration. J Craniovertebr Junction Spine 2010;1:65-6.

80. Goel A. Facet distraction-arthrodesis technique: Can it revolutionize spinal stabilization methods? J Craniovertebr Junction Spine 2011;2:1-2.

81. Goel A, Shah A, Patni N, et al. Immediate Postoperative Reversal of Disc Herniation Following Facetal DistractionFixation Surgery: Report of 4 Cases. World Neurosurg 2016;94:339-44.

82. McCormack BM, Bundoc RC, Ver MR, et al. Percutaneous posterior cervical fusion with the DTRAX Facet System for single-level radiculopathy: results in 60 patients. J Neurosurg Spine 2013;18:245-54.

83. Siemionow K, Janusz P, Glowka P. Cervical cages placed bilaterally in the facet joints from a posterior approach significantly increase foraminal area. Eur Spine J 2016;25:2279-85.

84. Siemionow KB, Glowka P, Blok RJ, et al. Perioperative complications in patients treated with posterior cervical fusion and bilateral cages. J Craniovertebr Junction Spine 2017;8:342-9.

85. Voronov LI, Siemionow KB, Havey RM, et al. Biomechanical evaluation of DTRAX $((\mathrm{R}))$ posterior cervical cage stabilization with and without lateral mass fixation. Med Devices (Auckl) 2016;9:285-90.

86. Cheng L, McCormack B, Eyster EF. Posterior cervical fusion utilizing cages placed bilaterally in the facets for the treatment of the upper cervical adjacent segment disease in the elderly. J Clin Neurosci 2019;63:149-54.

87. Hussain I, Schmidt FA, Kirnaz S, et al. MIS approaches in the cervical spine. J Spine Surg 2019;5:S74-83.

88. Henderson CM, Hennessy RG, Shuey HM, Jr., et al. Posterior-lateral foraminotomy as an exclusive operative technique for cervical radiculopathy: a review of 846 consecutively operated cases. Neurosurgery 1983;13:504-12 .

89. Murphey F, Simmons JC. Ruptured cervical disc. Experience with 250 cases. Am Surg 1966;32:83-8.

90. Zeidman SM, Ducker TB. Posterior cervical laminoforaminotomy for radiculopathy: review of 172 cases. Neurosurgery 1993;33:356-62.

91. Frykholm R. Deformities of dural pouches and strictures of dural sheaths in the cervical region producing nerveroot compression; a contribution to the etiology and operative treatment of brachial neuralgia. J Neurosurg 1947;4:403-13.

92. Scoville WB, Whitcomb BB, Mc LR. The cervical ruptured disc; report of 115 operative cases. Trans Am Neurol Assoc 1951;56:222-4.

93. Adamson TE. Microendoscopic posterior cervical laminoforaminotomy for unilateral radiculopathy: results of a new technique in 100 cases. J Neurosurg 2001;95:51-7.

94. Ruetten S, Komp M, Merk H, et al. Full-endoscopic cervical posterior foraminotomy for the operation of lateral disc herniations using 5.9-mm endoscopes: a prospective, randomized, controlled study. Spine (Phila Pa 1976) 2008;33:940-8.

95. Foster MT, Carleton-Bland NP, Lee MK, et al. Comparison of clinical outcomes in anterior cervical discectomy versus foraminotomy for brachialgia. $\mathrm{Br} \mathrm{J}$ Neurosurg 2019;33:3-7.

96. Selvanathan SK, Beagrie C, Thomson S, et al. Anterior cervical discectomy and fusion versus posterior cervical foraminotomy in the treatment of brachialgia: the Leeds spinal unit experience (2008-2013). Acta Neurochir (Wien) 2015;157:1595-600.

97. Dunn C, Moore J, Sahai N, et al. Minimally invasive posterior cervical foraminotomy with tubes to prevent undesired fusion: a long-term follow-up study. J Neurosurg Spine 2018;29:358-64.

98. Skovrlj B, Gologorsky Y, Haque R, et al. Complications, outcomes, and need for fusion after minimally invasive posterior cervical foraminotomy and microdiscectomy. Spine J 2014;14:2405-11.

99. Wang TY, Lubelski D, Abdullah KG, et al. Rates of anterior cervical discectomy and fusion after initial posterior cervical foraminotomy. Spine J 2015;15:971-6. 
100. Guiot BH, Khoo LT, Fessler RG. A minimally invasive technique for decompression of the lumbar spine. Spine (Phila Pa 1976) 2002;27:432-8.

101. Del Curto D, Kim JS, Lee SH. Minimally invasive posterior cervical microforaminotomy in the lower cervical spine and $\mathrm{C}-\mathrm{T}$ junction assisted by $\mathrm{O}$-arm-based navigation. Comput Aided Surg 2013;18:76-83.

102.Zhang C, Wu J, Xu C, et al. Minimally Invasive Full-Endoscopic Posterior Cervical Foraminotomy Assisted by O-Arm-Based Navigation. Pain Physician 2018;21:E215-23.

103.Zdeblick TA, Zou D, Warden KE, et al. Cervical stability after foraminotomy. A biomechanical in vitro analysis. J Bone Joint Surg Am 1992;74:22-7.

104.Zdeblick TA, Abitbol JJ, Kunz DN, et al. Cervical stability after sequential capsule resection. Spine (Phila Pa 1976) 1993;18:2005-8.

105.Spetzger U, Bertalanffy H, Naujokat C, et al. Unilateral laminotomy for bilateral decompression of lumbar spinal stenosis. Part I: Anatomical and surgical considerations. Acta Neurochir (Wien) 1997;139:392-6.

106. Palmer S, Turner R, Palmer R. Bilateral decompressive surgery in lumbar spinal stenosis associated with spondylolisthesis: unilateral approach and use of a microscope and tubular retractor system. Neurosurg Focus

Cite this article as: Kirnaz S, Gebhard H, Wong T, Nangunoori R, Schmidt FA, Sato K, Härtl R. Intraoperative image guidance for cervical spine surgery. Ann Transl Med 2021;9(1):93. doi: 10.21037/atm-20-1101
2002;13:E4.

107. Geck MJ, Eismont FJ. Surgical options for the treatment of cervical spondylotic myelopathy. Orthop Clin North Am 2002;33:329-48.

108. Bakhsheshian J, Mehta VA, Liu JC. Current Diagnosis and Management of Cervical Spondylotic Myelopathy. Global Spine J 2017;7:572-86.

109. Oppenheimer JH, DeCastro I, McDonnell DE. Minimally invasive spine technology and minimally invasive spine surgery: a historical review. Neurosurg Focus 2009;27:E9.

110.Hernandez RN, Wipplinger C, Navarro-Ramirez R, et al. Ten-Step Minimally Invasive Cervical Decompression via Unilateral Tubular Laminotomy: Technical Note and Early Clinical Experience. Oper Neurosurg (Hagerstown) 2020;18:284-94.

111. Kirnaz S, Wipplinger C, Wong T, et al. Less Invasive Cervical Decompression via Unilateral Tubular Laminotomy Using 3-Dimensional Total Navigation: 2-Dimensional Operative Video. Oper Neurosurg (Hagerstown) 2020;19:E418.

112. Minamide A, Yoshida M, Simpson AK, et al. Microendoscopic laminotomy versus conventional laminoplasty for cervical spondylotic myelopathy: 5-year follow-up study. J Neurosurg Spine 2017;27:403-9. 